\title{
The Second Spectrum of Nickel (Ni II) (Addenda and Errata)
}

\author{
A. G. Shenstone* \\ Institute for Basic Standards, National Bureau of Standards, Washington, D.C. 20234
}

(April 12, 1971)

This paper provides additional information which came to light too late for the original publication [J. Res. Nat. Bur. Stand. (U.S.) 74A, 801 (1970)].

Key words: Energy levels; ionization potential; nickel; spectral series; spectroscopy; wavelength.

This short paper is to provide additional information which came to light too late for the original publication of "The Second Spectrum of Ni (Ni II)." It is unfortunate but true that it is impossible to publish as complicated a paper as this one without some errors creeping in. Also, the very acts of preparing the paper for publication and the correcting of proof make evident some additions that should be made to the analysis.
1. One important line $\lambda 3709.456$ was inadverently omitted from Table I. It is included below in a list of changes.in that table.

2. A number of combinations between known levels were found. They are also listed below.

3. Two levels with which I was dissatisfied have been eliminated and new ones found to replace them. They are $\omega^{4} \mathrm{G}_{41 / 2}^{\circ}$ and $\omega^{4} \mathrm{G}_{21 / 2}^{\circ}$ and they are included below in a list of changes in Table III.

\section{Corrections and Additions to Table I}

\begin{tabular}{|c|c|c|c|c|c|}
\hline Page & $\lambda(\mathrm{vac})$ & Intensity & Wavenumber & Transition & Remarks \\
\hline $803 \ldots$ & 799.145 & 2 & 125133.74 & $4 s^{4} \mathrm{~F}_{41 / 2}-v^{4} \mathrm{~F}_{31 / 2}^{\circ}$ & Corrected $J$-Value \\
\hline $803 \ldots$ & 823.277 & 3 & 121465.80 & $4 s^{2} \mathrm{~F}_{21 / 2}-v^{2} \mathrm{D}_{11 / 2}^{\circ}$ & New level \\
\hline $803 \ldots$ & 898.821 & 5 & 111256.686 & $4 s^{\prime}{ }^{2} \mathrm{D}_{11 / 2}^{1 / 2}-w^{2} \mathrm{P}_{1 / 2}^{\circ / 2}$ & New level \\
\hline $803 \ldots$ & 906.906 & 1 & 110265.01 & $4 s^{\prime \prime}{ }^{4} \mathrm{P}_{11 / 2}-w^{2} \mathrm{P}_{1 / 2}^{\circ / 2}$ & New level \\
\hline $804 \ldots$ & 936.704 & 15 & 106757.31 & ........... & Identification deleted \\
\hline $804 \ldots$ & 940.886 & 20 & 106282.80 & $\begin{array}{c}3 d l^{2} \mathrm{D}_{21 / 2}-5 p^{4} \mathrm{G}_{21 / 2}^{\circ} \\
4 s^{4} \mathrm{~F}_{31 / 2}-w^{4} \mathrm{G}_{41 / 2}^{\circ}\end{array}$ & New level \\
\hline $804 \ldots$ & 941.972 & 10 & 106160.27 & $4 s{ }^{4} \mathbf{F}_{21 / 2}-w^{4} \mathrm{G}_{31 / 2}^{\circ}$ & One ident. deleted \\
\hline $804 \ldots$ & 942.587 & 5 & 106091.00 & $4 s^{4} \mathrm{~F}_{11 / 2}-w^{4} \mathrm{G}_{21 / 2}^{\circ}$ & New level \\
\hline $804 \ldots$ & 953.033 & 10 & 104928.16 & $4 s^{4} \mathrm{~F}_{41 / 2}-x^{4} \mathrm{~F}_{41 / 2}^{\circ}$ & One ident. deleted \\
\hline $807 \ldots$ & 1308.869 & 16 & 76401.84 & $3 d^{2} \mathrm{D}_{21 / 2}-4 p^{\prime \prime} .{ }^{\prime \prime 2} \mathrm{~F}_{21 / 2}^{\circ}$ & New combination \\
\hline $809 \ldots$ & 1452.558 & 15 & 68844.07 & $s^{2}{ }^{4} \mathrm{~F}_{31 / 2}-5 p^{\prime \prime 4} \mathrm{D}_{21 / 2}^{\circ}$ & New combination \\
\hline $812 \ldots$ & 1547.547 & 3 & 64618.39 & $s^{2}{ }^{2} \mathrm{G}_{31 / 2}-v^{2} \mathrm{G}_{41 / 2}^{\circ}$ & One ident. deleted \\
\hline $812 \ldots$ & 1565.399 & 20 & 63881.48 & 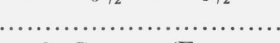 & Identification deleted \\
\hline $812 \ldots$ & 1574.942 & 20 & 63494.40 & $s^{2}{ }^{2} \mathrm{G}_{41 / 2}-v^{4} \mathrm{~F}_{41 / 2}$ & New combination \\
\hline $812 \ldots$ & 1577.115 & 16 & 63406.92 & $4 p^{2} \mathrm{D}_{11 / 2}^{\circ}-5 d^{2} \mathrm{P}_{1 / 2}$ & \\
\hline & & 10 & 63222.95 & $s^{2}{ }^{4} \mathrm{~F}_{31 / 2}-w{ }^{4} \mathrm{G}_{41 / 2}^{\circ}$ & $\begin{array}{l}\text { New level } \\
\text { Identification deleted }\end{array}$ \\
\hline $813 \ldots$ & $\begin{array}{l}1581.704 \\
1583.436\end{array}$ & $\begin{array}{l}10 \\
10\end{array}$ & 63153.80 & $s^{2}{ }^{4} \mathrm{~F}_{11 / 2}-w^{4} \mathrm{G}_{21 / 2}^{\circ}$ & New level \\
\hline $813 \ldots$ & 1598.282 & 40 & 62567.18 & $s^{2}{ }^{2} \mathrm{P}_{11 / 2}-v^{2} \mathrm{D}_{41 / 2}^{\circ}$ & New level \\
\hline $813 \ldots$ & 1602.679 & 1 & 62395.53 & $s^{2}{ }^{2} \mathrm{G}_{31 / 2}-v{ }^{4} \mathrm{~F}_{41 / 2}^{\circ / 2}$ & New combination \\
\hline $814 \ldots$ & 1613.132 & 2 & 61991.21 & $s^{2}{ }^{4} \mathrm{P}_{11 / 2}-5 f^{4} \mathrm{P}_{1 / 2}^{\circ}$ & One ident. deleted \\
\hline $814 \ldots$ & 1635.070 & 30 & 61159.46 & $s^{2}{ }^{2} \mathrm{P}_{11 / 2}-w^{2} \mathrm{P}_{1 / 2}^{\circ}$ & New level \\
\hline $815 \ldots$ & 1691.231 & 11 & 59128.53 & $s^{2}{ }^{2} \mathrm{D}_{21 / 2}-v^{2} \mathrm{D}_{21 / 2}^{\circ}$ & New level \\
\hline $815 \ldots$ & 1729.625 & 6 & 57815.98 & $s^{2}{ }^{4} \mathrm{~F}_{31 / 2}-y{ }^{4} \mathrm{G}_{41 / 2}^{\circ}$ & Corrected $\lambda$ and $\nu$ \\
\hline $830 \ldots$ & 3769.456 & 50 & 26521.49 & $4 s^{\prime \prime}{ }^{4} \mathrm{P}_{21 / 2}-4 p^{4} \mathrm{D}_{31 / 2}^{\circ}$ & Added line \\
\hline
\end{tabular}

*Present address: Department of Physics, Princeton University, Princeton, N.J. 08540. 
Additions to Table III

\begin{tabular}{l|c|c|c|c|l}
\hline \hline Configuration & Name & $\begin{array}{c}\text { Level } \\
\text { observed }\end{array}$ & $\begin{array}{c}\text { Level } \\
\text { computed }\end{array}$ & O-C & \multicolumn{1}{|c}{ Remarks } \\
\hline $3 d^{7}\left({ }^{2} \mathrm{H}\right) s p\left({ }^{3} \mathrm{P}\right)$ & $w^{4} \mathrm{G}_{41 / 2}^{\circ}$ & 115612.88 & 115529 & +84 & Replaces 116087 \\
$3 d^{7}\left({ }^{2} \mathrm{H}\right) \operatorname{sp}\left({ }^{3} \mathrm{P}\right)$ & $w^{4} \mathrm{G}_{21 / 2}^{\circ}$ & 116754.93 & 116614 & +141 & Replaces 116824 \\
$3 d^{7}\left({ }^{2} \mathrm{P}\right) \operatorname{sp}\left({ }^{1} \mathrm{P}\right)$ & $w^{2} \mathrm{P}_{1 / 2}^{\circ}$ & 135053.14 & 135657 & -604 & New level \\
$3 d^{7}\left({ }^{2} \mathrm{P}\right) \operatorname{sp}\left({ }^{1} \mathrm{P}\right)$ & $v^{2} \mathrm{D}_{11 / 2}^{\circ}$ & 136461.10 & 137113 & -652 & New level \\
\hline
\end{tabular}

4. The levels of $\omega^{4} \mathrm{D}^{\circ}$ are doubtful because each of them depends on only two lines, one of which is doubly assigned.

The levels $y^{4} \mathrm{G}_{31 / 2}^{\circ}$ and $y^{4} \mathrm{G}_{41 / 2}^{\circ}$ may be spurious and $x^{4} \mathrm{~F}_{11 / 2}$ is definitely so and should be discarded. The line list includes all the lines which were assigned to this level.

5. Two new levels whi h I assign to $3 d^{7}\left({ }^{2} \mathrm{P}\right) \operatorname{sp}\left({ }^{1} \mathrm{P}\right)$ as $\omega^{2} \mathrm{P}_{1 / 2}^{\circ}(135053.14)$ and $\nu^{2} \mathrm{D}_{11 / 2}^{\circ}(136461.10)$ have been found. They are companions to known doublet levels.

The analysis of Ni II is by no means complete, but it could not have been carried even as far as it has been without the essential aid of Professor Shadmi. That is not to say that we are in complete agreement on all of the allocations of levels to the calculated terms. Our failures to agree arise, I think, from the fact that the theorist's chief concern is the numerical fit whereas the experimentalist is interested in other criteria, specifically in this case the intensities of combinations. I believe my allocations are more realistic because most levels do show rather definite characters when the intensities are examined. I shall quote only two cases.

In the group of levels $3 d^{8}\left({ }^{3} \mathrm{~F}\right) 5 p$ there are three levels with $J=4 \frac{1}{2}$. Their total intensities of combination with quartet and doublet levels are approximately as follows: 1500 to 15 for 104081,2000 to 15 for 104298 and 45 to 1000 for 105588. Professor Shadmi chooses the first of these as ${ }^{2} \mathrm{G}_{41 / 2}$ and the last as ${ }^{4} \mathrm{G}_{41 / 2}$, a choice no experimentalist would ever make. A second example is my $x^{4} \mathrm{G}_{31 / 2}$, for which Shadmi's assignment is ${ }^{4} \mathrm{D}_{31 / 2}$. The intensities of combination with the $4 \frac{1}{2}, 3^{1 / 2}, 2^{1 / 2}$ of $s^{2}{ }^{4} \mathrm{~F}$ are $2,8,25$ which is perfect for ${ }^{4} \mathrm{G}_{31 / 2}$ and could not be worse for ${ }^{4} \mathrm{D}_{31 / 2}$.

6. Table II, page 843, fourteen Observed Levels 52205.95 to 78955.45 inclusive, the "Configuration" column should be corrected to read $3 d^{7} 4 s^{2}$.

7. Table II, page 845, thirteen Observed Levels 128924.94 to 128966.52 inclusive, the "Configuration" column should be corrected to read $3 d^{8}\left({ }^{3} \mathrm{~F}_{4}\right) 5 \mathrm{~g}$.

8. Table II, page 846, three Observed Levels 134334.46 to 134336.68 inclusive, the "Configuration" column should be corrected to read $3 d^{8}\left({ }^{3} \mathrm{~F}_{4}\right) 6 g$.

9. Table III, page 849 , the name of the Observed Level 118877.09 should read $4 f^{4} \mathrm{P}_{11 / 2}^{\circ}$ instead of $4 f^{4} \mathrm{P}_{71 / 2}^{\circ}$.

10. Table III, page 852 , the name of the level 135746.06 should read $v^{2} \mathrm{G}_{31 / 2}^{\circ}$ instead of $o^{2} \mathrm{G}_{31 / 2}^{\circ}$.

There are four levels which Shadmi has been unable to fit at all into the scheme. The level $\nu^{2} \mathrm{D}_{21 / 2}$ at 135258.88 is undoubtedly real, making one combination with a quartet level and four with doublet levels. The term $v^{4} \mathrm{P}$ which fails to fit by such very large amounts appears to be real from the experimental evidence.

I hope that in the future I can continue to get such great help from my friends in the Bureau of Standards and Israel as I have had during the past years when I was engaged in the analysis of Ni II. 